\title{
THE USE OF OXYGEN IN OUT-OF HOSPITAL CARDIAC ARREST- EURECA_VOJVODINA
}

Mihaela Budimski , Kornelija Jakšič Horvat', Snežana Holcer Vukelić

\section{Sažetak: \\ Cilj radat}

cilj rada je da se ustanovi da li postoji statistički značajna razlika primene kiseonika kod pacijenata sa vanbolničkim srčanim zastojem na licu mesta ili u sanitetskom vozilu kao i načina zbrinjavanja disajnog puta u odnosu na uspostavljenu spontanu cirkulaciju.

\section{Metodologija rada:}

U metodologiji rada obrađivani podaci iz registra EuReCa_Srbija za period januar 2016.-jun 2017. godine. $U$ analizi su upotrebljeni podaci iz registra EuReCa koji sadrži jedinstvenu bazu podataka u koju su glavni istraživači unosili podatke prikupljene intervenisanjem Službi hitnih medicinskih pomoći kod pacijenata koji su doživeli vanbolnički srčani zastoj na teritoriji Vojvodine u posmatranom periodu. Statistička obrada podataka je izvršena primenom programskog paketa SPSS. Primenjena je analiza varijanse.

\section{Rezultati:}

na teritoriji Vojvodine potvrđeno je ukupno 589 vanbolničkih srčanih zastoja od strane lekarskih ekipa hitnih medicinskih pomoći (HMP) u priodu januar 2016-jun 2017. Mere kardiopulmonalne resuscitacije (KPR) su započete kod 419/589 (71\%) pacijenata, od kojih je 144/419 (34\%) osoba ženskog pola, a 275/419 (66\%) muškog. Prosečna starost je 65,3 godina. Sokabilni inicijalni ritam (vetrikularna tahikardija bez pusa VT /ventrikularna fibrilacija VF) je zabeležen 123 /419 put (29\%) dok je nešokabilan ritam (asistolija/bezpulsna električna aktivnost PEA) imalo 296/419 pacijenata (71\%). Povratak spontane cirkulacije (ROSC) je uspostavljen kod 144/419 (34\%) pacijenata. Do otpusta iz bolnice je preživelo $17 / 419$ pacijenata (4\%) a nakon 30 dana 16/419 $(4 \%)$. Kiseonik je primenjen kod 179/419 (43\%) pacijenata, nije dat kod 240 (57\%)pacijenta. Na licu mesta je kiseonik primenjen kod 138/179 pacijenata $(77 \%)$, dok je u sanitetskom vozilu dat kod $40 / 179$ pacijenata $(23 \%)$. Samošireći balon je upotrebljen kod 35/276 pacijenata (13\%), LM 14/276 (5\%), I gel 32/276 (12\%) i ETI 194/276 odn (70\%). Na osnovu statističke obrade podataka mesta primene kiseonične terapije kao i načina zbrinjavanja disajnog puta, dobija se rezultat koji ukazuje da upotreba kiseonika kao i mesto upotrebe kiseonika statistički značajno utiču na ROSC, uz rizik greške manji od $1 \%(p<0,01)$. Postoji statistički značajan uticaj na ROSC u zavisnosti od toga da li je dat kiseonik na licu mesta ili onaj koji se daje u kolima. Rezultati ove analize pokazuju da obezbeđen disajni put kao ni način obezbeđivanja disajnog puta ne utiču statistički značajno na ROSC. ROSC ne zavisi statistički značajno od toga da li je korišćen: samošireći balon, Igel, LMA i ETI.

\section{Zaključak}

rezultati našeg istraživanja su ukazali da upotreba kiseonika kao i mesto upotrebe kiseonika statistički značajno utiču na uspostavljanje spontane cirkulacije kod pacijenata sa vanbolničkim srčanim zastojem. Način obezbeđivanja disajnog puta ne utiče statistički značajno na ROSC. Potrebne su dalje analize koji bi ukazale koji su sve mogući razlozi i faktori koji dovode do toga da se kiseonik u određenom procentu ne upotrebljava kod pacijenata sa iznenadnim srčanim zastojem.

\section{USTANOUA}

Dom zdravlja Subotica

2 Dom zdravlja "dr Đorđe Lazić"

Sombor

\section{AUTOR ZA}

\section{KORESPODENCIJU:}

Mihaela Budimski

Dom zdravlja Subotica

mail: dzsupiar@gmail.com

\begin{abstract}
Aim:

The aim of the study was focused to determine is there a stastistically significant difference of the use of oxygen during out-of hospital cardiac arrest (OHCA) patients on scene or in the ambulance car during transport and the airway management compared to achieved return of spontaneous circulation (ROSC).
\end{abstract}

\section{Methods:}

During this study, the datas' form EuReCa_Srbija register have been used for the period January 2016 -June 2017. The analyzed data's from EuReCa Srbija register has been uploaded by lead investigators, collected during emergency medical services (EMS) interventions in patients with OHCA in Vojvodina. The statistical program of SPSS processed collected data's. The analizes of variance was applied.

\section{Results:}

In observed period in Vojvodina, 589 OHCA accured and treated by EMS CPR was applied in Mere $419 / 589(71 \%)$ cases where $144 / 419(34 \%)$ were female and $275 / 419(66 \%)$ male gender. The average year was 65,3 . The initial shockable rhythm (pulseless ventricular tachycardia pVT /ventricular fibrillation VF) was registered in $123 / 419$ (29\%), while nonshockable rhythm (asistoly/pulseless electrical activity PEA) in 296/419 $(71 \%)$ patients. ROSC was achieved in $144 / 419(34 \%)$ cases. The hospital survival was present in $17 / 419(4 \%)$ and after 30 days was $16 / 419(4 \%)$ Oxygen was applied in 179/419 (43\%) cases, at $240(57 \%)$ was not used. On scene the oxygen havs been used in $138 / 179(77 \%)$ cases, during transport in 40/179 (23\%). Bag-valve-mask was used in 35/276 (13\%) patients, LMA in $14 / 276(5 \%)$, l-gel in $32 / 276(12 \%)$ and ETI in 194/276 $(70 \%)$. Based on the used oxygen therapy and airway management's collected data's, the results indicate that the use of oxygen and the spot where it is used significantly influence the ROSC, where the risk of error is lower than $1 \% \quad(p<0,01)$. There is statistically significant influence on ROSC, depending on was the oxygen given on the scene or in the ambulance car during the transport. The results are showing that the way of the airway management does not influence ROSC statistically.. ROSC statistically does not depend on the use of bag-valve-mask, I-gel, LMA and/or ETI.

\section{Conclusion:}

The result of observed data's showed that the place and the use of oxygen have statistically significant influence to achieve ROSC in patients with OHCA. The airway management itself does not have influence on ROSC. Further analysis are needed regarding the underlying factors and reasons that could lead that the oxygen is not used regularly in patients with cardiac arrest.

\section{KLJUČNE REČl:}

vanbolnički srčani zastoj, KPR kiseonik, služba hitne medicinske pomoći

\section{KEY WORDS:}

out-of hospital cardiac arrest, CPR, oxygen, emergency medical service
DATUM PRIJEMA RADA

24. jul 2018.

DATUM PRIHUATANA RADA 21. avgust 2018. Datum OBJaVLUVANIA

24. septembar 2018 


\section{UVOD:}

Uključivanje R. Srbije u program EuReCa One 2014. godine je doprinelo praćenju pojave vanbolničkog srčanog zastoja kroz upitnik postavljenim programom studije i omogućila razmenu informacija sa EURECA registrima drugih Evropskih zemalja(1). Kontinuinalno praćenje i sistemske analize su dovele do niza pitanja koja su se ticala načina i kvaliteta zbrinjavanja vanbolničkog srčanog zastoja. Parametri koji su praćeni studijom su se vremenom proširivali i obuhvatili su detaljnije informacije o načinu tretiranja pacijenata, o udaljenosti pacijenata od ekipe službe hitne medicinske pomoći koja je poslata da ga zbrine, o primeni kiseonika i načinu obezbeđivanja disajnog puta. U Srbiji ne postoji opis standardne procedure, kao ni dizajniran obrazac za praćenje vitalnih parametara pacijenata ni kao deo nacionalnih indikatora kvaliteta rada niti indikatora koje ima pravo da uspostavi ustanova - internih indikatora kvaliteta rada(2). Uz registar EuReCa Srbija, dobićemo odgovore na mnoge dileme a jedna od njih se tiče upotrebe kisaonika kod pacijenata sa vanbolničkim srčanim zastojem.

\section{CILJ RADA:}

Cilj rada je da se ustanovi da li postoji statistički značajna razlika primene kiseonika kod pacijenata sa vanbolničkim srčanim zastojem na licu mesta ili u sanitetskom vozilu kao i načina zbrinjavanja disajnog puta u odnosu na uspostavljenu spontanu cirkulaciju.

\section{METODOLOGIJA RADA:}

Program EuReCa je prospektivna, opservaciona, multicentrična studija koja je zavedena pod kliničkim tijalom pod brojem Clinical Trials ID: NCT03130088 a odobrena od zdravstvenih autoriteta SAD. Putem jedistvenog upitnika registruju se EuReCa događaji pacijenata sa vanbolničkim srčanim zastojem kod kojih je intervenisala HMP. Glavni istraživači ustanova koje učestvuju u projektu unuse podatke o EuReCa događajima u bazu putem adrese www.eureca.rs. U metodologiji rada su obrađivani podaci iz registra EuReCa Srbija za period januar 2016.-jun 2017. godine na teritoriji Vojvodine u posmatranom periodu. Statistička obrada podataka je izvršena primenom programskog paketa SPSS. Primenjena je analiza varijanse, kojom se ispituje efekat jedne ili više nezavisnih promenljivih na jednu zavisnu promenljivu. Nezavisno promenljive se nazivaju faktori uticaja i oni sadrže više nivoa (grupa), a njihov efekat se odražava na nivo zavisno promenljive.

\section{REZULTATI:}

Na teritoriji Vojvodine potvrđeno je ukupno 589 vanbol- ničkih srčanih zastoja od strane lekarskih ekipa hitnih medicinskih pomoći (HMP) u priodu januar 2016-jun 2017. Mere kardiopulmonalne resuscitacije (KPR) su započete kod 419/589 (71\%) pacijenata, od kojih je 144/419 (34\%) osoba ženskog pola, a 275/419 (66\%) muškog. Prosečna starost je 65,3 godina. Najmlađi pacijent je imao manje od godinu a najstariji 94 godina. Prema etiologiji, kardiovaskularni uzrok je najučestaliji 363/419 (87\%), dok se respiratorni etiološki uzrok javlja u 18/419 (4\%), trauma 5/419 (1\%) i nekardiološki uzroci u 28/419 (7\%). Prema mestu nastanaka srčanog zastoja prebivalište je najčešče 295/419 (70\%), zatim ulica 35/419 (8\%), dom za stare 8/419 (2\%), javna ustanova $21 / 419(5 \%)$, radno mesto $10 / 419(2 \%)$. Kolaps se desio pred svedokom u 280/419 (67\%) slučaja. Svedok očevidac je započeo KPR pre dolaska ekipa hitne medicinske pomoći kod 80/419 pacijenata sa VBSZ (19\%). Telefonski vođen KPR je kod 53/419 osobe (13\%). Šokabilni inicijalni ritam (vetrikularna tahikardija bez pusa VT /ventrikularna fibrilacija VF) je zabeležen 123 /419 put (29\%) dok je nešokabilan ritam (asistolija/bezpulsna električna aktivnost PEA) imalo 296/419 pacijenata (71\%). Spoljašnji automatski defibrilator (AED) se ni jednom nije primenio. Povratak spontane cirkulacije (ROSC) je uspostavljen kod 144/419 (34\%) pacijenata. Do otpusta iz bolnice je preživelo $17 / 419$ pacijenata ( $4 \%)$ a nakon 30 dana 16/419 (4\%). Kiseonik je primenjen kod 179/419 (43\%) pacijenata, nije dat kod 240 (57\%)pacijenta, grafikon 1. Na licu mesta je kiseonik primenjen kod $138 / 179$ pacijenata $(77 \%)$, dok je u sanitetskom vozilu dat kod 40/179 pacijenata (23\%). Samošireći balon je upotrebljen kod 35/276 pacijenata (13\%), LM 14/276 $(5 \%)$, I gel 32/276 (12\%) i ETI 194/276 odn (70\%), grafikon 2. Posmatrajući pacijente kod kojih je uspostavljena spontana cirkulacija (ROSC), kiseonik je primenjen kod 105/144 (73\%) pacijenata a kod 39/144 (27\%) nije. Pacijenti kod kojih je dat kiseonik inicijalno su imali šokabilan ritam (pVT/VF) 48/105 (46\%), a 57/105 (54\%) je inicijalno bilo u nešokabilnom ritmu (asistolija/PEA). Za zbrinjavanje disajnog puta kod pacijenata u inicijalno šokabilnom ritmu a kod kojih je postignut ROSC, najčešče je korištena ETI 29/48 (60\%), I gel 7/48 (14,5\%), LM 2/48 (4\%), samošireći balon 5/48 (10\%) a kod 5/48 $(10 \%)$ pacijenata nije zbrinut disajni put a kiseonik je dat u sanitetskom vozilu. Na osnovu statističke obrade podataka mesta primene kiseonične terapije kao i načina zbrinjavanja disajnog puta, dobija se rezultat koji ukazuje da upotreba kiseonika kao i mesto upotrebe kiseonika statistički značajno utiču na ROSC, uz rizik greške manji od 1\% ( $p<0,01)$. Postoji statistički značajan uticaj na ROSC u zavisnosti od toga da li je dat kiseonik na licu mesta ili onaj koji se daje u kolima, tabela 1 i 2 . Rezul- 
tati ove analize pokazuju da obezbeđen disajni put kao ni način obezbeđivanja disajnog puta ne utiču statistički značajno na ROSC. ROSC ne zavisi statistički značajno od toga da li je korišćen: samošireći balon, Igel, LMA i ETI, tabela 3 i 4.

\section{DISKUSIJA:}

Pacijenti koji zahtevaju KPR često imaju opstruisan disajni put, obično uzrokovanim gubitnom svesti. Kontrola prohodnosti disajnog puta i obezbeđivanje ventilacije, ukoliko je potrebno, su od ključnog značaja u prevenciji sekundarnog hipoksičnog oštećena mozga i drugih vitalnig organa. Bez odgovarajuće oksigenacije nije moguće uspostaviti organizovan srčani ritam (3). Zbrinjavanje disajnog puta tokom kardiopulmonalne resuscitacije zavise od faktora koji proističu od samog pacijenta, veština spasioca tako i od faze u kojoj se nalazi resuscitacija (4). Ukoliko je srčani zastoj osvedočen u prisustvu defibrilatora, prioritet ima neposredna defibrilacija a nakon toga zbrinjavanje disajnog puta (3). Analiza naše studije ukazuje da je od značaja upotreba kiseonika na licu mesta kolapsa pacijenta a da se način na koji se disajni put obezbeđuje ne utiče statistički značajno na uspostavljanje spontane cirkulacije. I drugi autori su u svojim istraživanjima došli do sličnih rezultata. Le Blanc u svojom studiji dolazi do zaključka da kontinuinalna insuflacija kiseonika tokom resuscitacije u poređenju sa standardnom primenom ventilacije samoširećim balonom ili endotrahealnom intubacijom i mehaničkom ventilacijom ne dovode do povećanja uspostavljanja spontane cirkulacije niti preživljavanja (5). Međutim, grupa autora iz Japana (6) je u svojoj studiji došla do zaključka da je upotreba ranog naprednog obezbeđivanja disajnog puta (u prvih pet minuta) povezano sa znatno višim funkcionalnim jednomesečnim preživljavanjem $(2,2 \%$ naspram $1,4 \%$ ). $U$ istom radu ističu da na preživljavanje nije značajno uticala starost ili pol pacijenta, početni ritam ili način za obezbeđivanje disajnog puta (intubacija vs. supraglotično sredstvo). Nasuprot zaključku prethodno navedene studije, meta-analiza opservacione studije vanbolničkog srčanog zastoja (7) ukazuje da je napredno zbrinjavanje disajnog puta povezano sa nižim procentom preživnjavanja do bolničkog otpusta i 30 dana od otpusta u poređenju sa preživljavanjem pacijenata kod kojih je upotrebljen samošireći balon. Ova opservaciona studija dovodi do različitih dilema jer kod pacijenata kod kojih je ROSC brzo postignut, napredno zbrinjavanje disajnog puta možda nije ni bilo potrebno za razliku od pacijenata sa primarnom asfiksijom ili gastričnom regurgitacijom, kod kojih je ono neophodno (8). U našoj analizi, pacijentima se disajni put zbrinjava u najvećem procentu endotrahealnom intubacijom i supraglotičnim sredstvom (I gel). Čak i kod pacijenta koji su inicijalno u šokabilnom ritmu, obezbeđivanje disajnog puta je u visokom procentu, dok kod $20 \%$ pacijenata ono nije bilo neophodno i kiseonik se koristio u postresuscitacionoj nezi do transporta u zdravstvenu ustanovu. Prema ERC preporukama nakon uspostavljanja spontane cirkulacije (ROSC), oksigenaciju bi trebalo održavati između 94-98\% monitoringom pulsne oksimetrije (9). Ovaj parametar nije praćen tokom naše studije te bi dalja opservacija monitoringa u postresuscitaciji mogla dati odgovore na druga pitanja, kao što su neurološki odgovor pacijenata kao i potreba za mehaničkom ventilacijom nakon resuscitacije. Kapnografija se preporučuje tokom KPR i nakon uspostavljanja spontane cirkulacije a predstavlja parametar koji nije obuhvaćen našom studijom a kojem bi trebalo posvetiti pažnju u narednom periodu. Brojni radovi ukazuju na važnost primene kiseonika u postresuscitacionoj nezi kao i o njegovoj toksičnosti $(10,11,12)$. Praćenje pacijenata nakon uspostavljanja spontane cirkulacije (ROSC) i analiza vitalnih parametara iz jedinica intenzivne nege bi omogućila, uz dobru saradnju sa zdravstvenim ustanovama sekundarnog i tercijanog nivoa, da se dobiju detaljni podaci o pacijentima koji se tretiraju hospitalno. Istraživanja (13) ukazuju da postoje dva ključna perioda kada se mortalitet može očekivati: rano (tokom prva tri dana), obično zbog recidivantnog srčanog zastoja ili ozbiljnog kardiovaskularnog kolapsa, što dovodi do multiorganske insuficijencije, ili kasnije (nakon trećeg dana), obično sekundarno u odsustvu neurološkog oporavka. Na ovaj način bi bilo omogućeno da se razjasni koji sve faktori utiču da pacijenti, koji su nakon prijema u bolnicu, doživeli ponovni srčani zastoj. Studija (14) sprovedena u Švajcarskoj ukazuje na različite prediktore mortaliteta nakon uspostavljanja ROSC. U njihovom istraživanju 5,7\% pacijenata sa ROSC-om koji su umrli tokom zbrinjavanja na urgentnim odeljenjima su bili pretežno ženskog pola, starije životne dobi, pacijenti sa dužim trajanjem KPR-a kao i pacijenti sa nešokabilnim inicijalnim srčanim ritmom. Kod pacijenata kod kojih je rađen tokom transporta KPR koji je nastavljen po prijemu u bolnicu, nisu ustanovljeni klinički niti faktori od strane pacijenata koji su doveli do smrtnog ishoda(14).

\section{ZAKLUČAK:}

Rezultati našeg istraživanja su ukazali da upotreba kiseonika kao i mesto upotrebe kiseonika statistički značajno utiču na uspostavljanje spontane cirkulacije kod pacijenata sa vanbolničkim srčanim zastojem. Način obezbeđivanja disajnog puta ne utiče statistički značajno na ROSC. Potrebne su dalje analize koji bi ukazale koji su sve mogući razlozi i faktori koji dovode do toga da 
se kiseonik u određenom procentu ne upotrebljava kod pacijenata sa iznenadnim srčanim zastojem.

Grafikon 1. Upotreba kiseonika kod pacijenata sa vanbolničkim srčanim zastojem

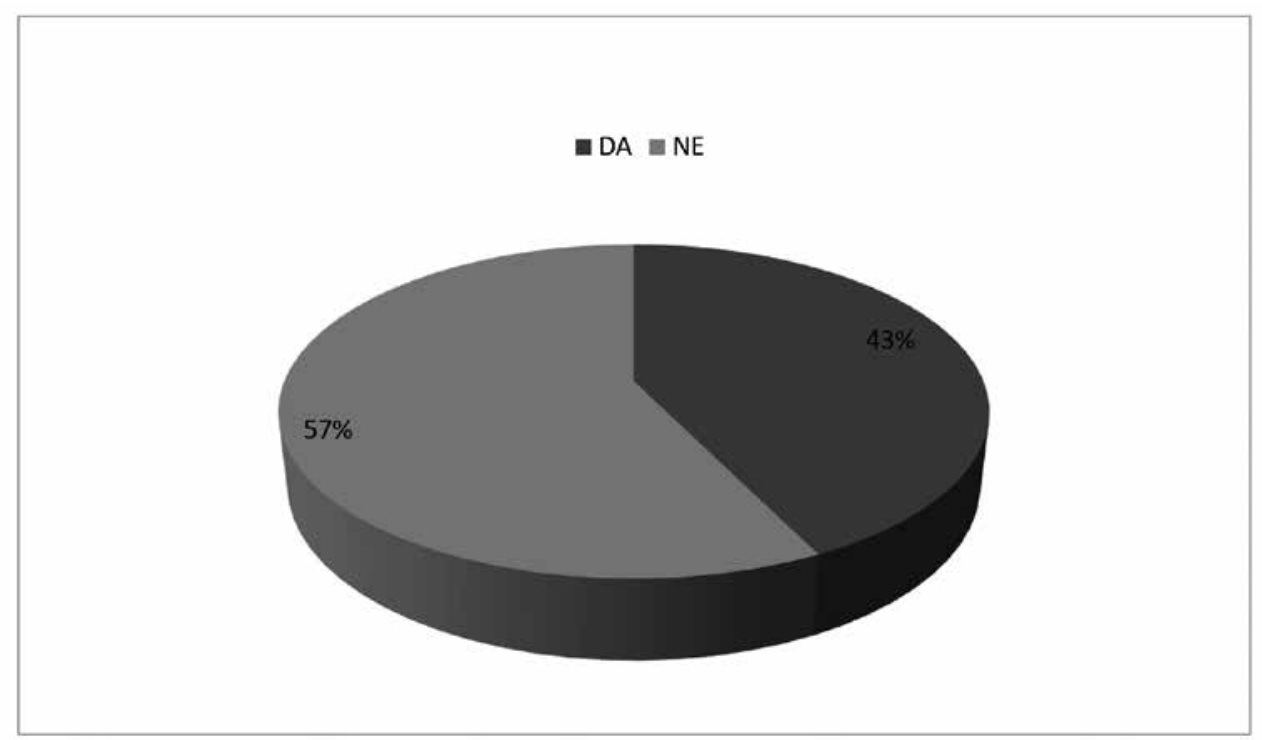

Grafikon 2. Način zbrinjavanja disajnog puta kod pacijenata sa VBSZ

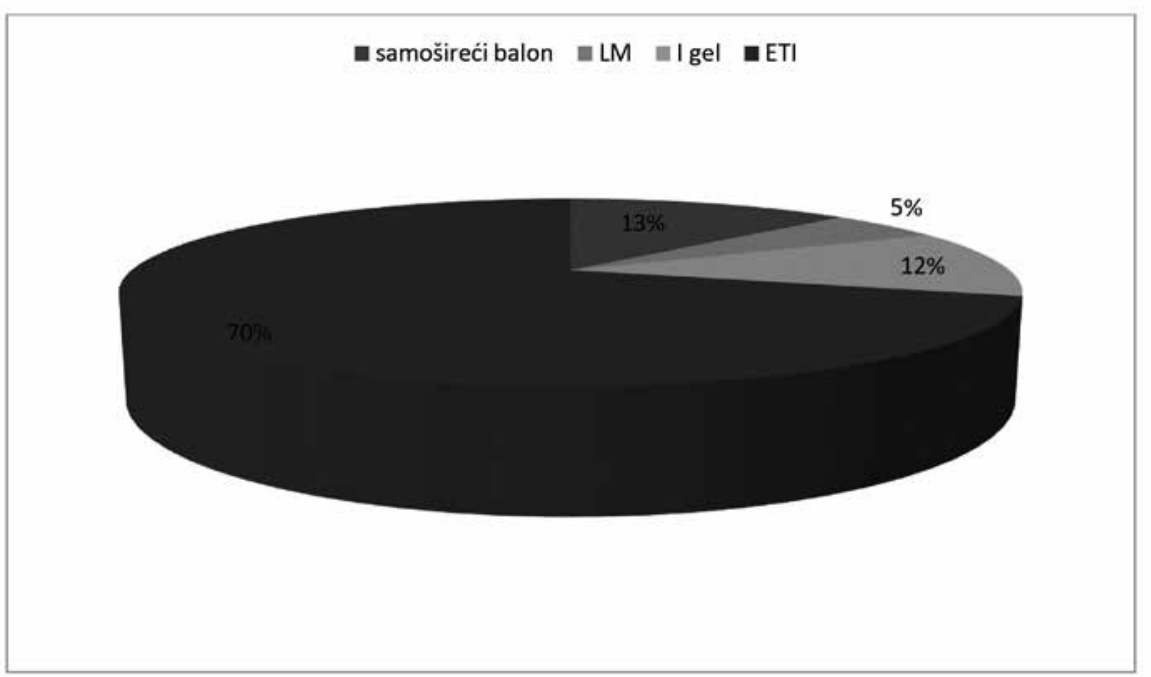

\section{Lista skraćenica}

\begin{tabular}{|l|l|}
\hline VBSZ & vanbolnički srčani zastoj \\
\hline KPR & kardiopulmonalna resuscitacija \\
\hline HMP & hitna medicinska pomoć \\
\hline TSZ & traumatski srčani zastoj \\
\hline pVT & ventrikularna tahikardija bez pulsa \\
\hline VF & ventrikularna fibrilacija \\
\hline PEA & električna aktivnost bez pulsa \\
\hline AED & automatski spoljašnji defibrilator \\
\hline ROSC & povratak spontane cirkulacije \\
\hline VS & versus - naspram \\
\hline LM & laringealna maska \\
\hline I gel & supraglotično sredstvo -I gel \\
\hline ETI & endotrahealna intubacija \\
\hline
\end{tabular}

\section{Konflikt interesa:}

Autor i koautori izjavljuju da nemaju konflikt interesa. Zahvalnost:

Autori se zahvaljuju svim učesnicima na pomoći u prikupljanju podataka kao i Resuscitacionom Savetu Srbije. Finansijska podrška:

Istraživanje je finansirano od strane Resuscitacionog Saveta Srbije iz sredstava članarine. Autori i koautori nemaju naknadu za učešće u studiji, obradu i saopštavanje rezultata. 
Tabela 1. Primena kiseonika kod VBSZ

ROSC

\begin{tabular}{|l|l|l|l|l|l|} 
& $\begin{array}{l}\text { Sum of } \\
\text { Squares }\end{array}$ & df & $\begin{array}{l}\text { Mean } \\
\text { Square }\end{array}$ & $F$ & Sig. \\
\hline $\begin{array}{l}\text { Between } \\
\text { Groups }\end{array}$ & 9,560 & 1 & 9,560 & 58,720 &, 000 \\
\hline $\begin{array}{l}\text { Within } \\
\text { Groups }\end{array}$ & 21,654 & 133 &, 163 & & \\
\hline Total & 31,215 & 134 & & & \\
\hline
\end{tabular}

Tabela 2. Mesto primene kiseonika

ROSC

\begin{tabular}{l|l|l|l|l|l|} 
& $\begin{array}{l}\text { Sum of } \\
\text { Squares }\end{array}$ & df & $\begin{array}{l}\text { Mean } \\
\text { Square }\end{array}$ & $F$ & Sig. \\
\hline $\begin{array}{l}\text { Between } \\
\text { Groups }\end{array}$ & 12,218 & 2 & 6,109 & 42,451 &, 000 \\
\hline $\begin{array}{l}\text { Within } \\
\text { Groups }\end{array}$ & 18,996 & 132 &, 144 & & \\
\hline Total & 31,215 & 134 & & & \\
\hline
\end{tabular}

\section{Tabela 3. Način zbrinjavanja disajnog puta}

ROSC

\begin{tabular}{|l|l|l|l|l|l|} 
& $\begin{array}{l}\text { Sum of } \\
\text { Squares }\end{array}$ & df & $\begin{array}{l}\text { Mean } \\
\text { Square }\end{array}$ & $F$ & Sig. \\
\hline $\begin{array}{l}\text { Between } \\
\text { Groups }\end{array}$ & 1,595 & 4 &, 399 & 1,751 &, 143 \\
\hline $\begin{array}{l}\text { Within } \\
\text { Groups }\end{array}$ & 29,619 & 130 &, 228 & & \\
\hline Total & 31,215 & 134 & & & \\
\hline
\end{tabular}

Tabela 4. Da li je obezbeden disajni put

ROSC

\begin{tabular}{|l|l|l|l|l|l|}
\hline & $\begin{array}{l}\text { Sum of } \\
\text { Squares }\end{array}$ & df & $\begin{array}{l}\text { Mean } \\
\text { Square }\end{array}$ & $F$ & Sig. \\
\hline $\begin{array}{l}\text { Between } \\
\text { Groups }\end{array}$ & 191 & 1 &, 191 &, 819 &, 367 \\
\hline $\begin{array}{l}\text { Within } \\
\text { Groups }\end{array}$ & 31,024 & 133 &, 233 & & \\
\hline Total & 31,215 & 134 & & & \\
\hline
\end{tabular}

\section{Literatura:}

1. Fišer Z, Raffay V, Slađana Vlajović S. et. al. Program praćenja pojave srčanog zastoja EURECA ONE Srbija 2014. Journal Resuscitatio Balcanica 2015; 1:5-8.

2. Fišer Z., Tijanić J., Budimski M. Lanac prevencije i njegova implementarnost u Republici Srbiji. Journal Resuscitatio Balcanica 2016; 2: 9-11.

3. Perkins GD, Olasveengen TM, Maconochie I, Soar J, Wyllie J, Greif R, Lockey A, Semeraro F, Van de Voorde $P$, Lott $C$, et al. European resuscitation council guidelines for resuscitation: 2017 update. Resuscitation. 2017;123:43-50.
4. Jevđić J, Raffay V. et. al. Održavanje disajnog puta i ventilacija. U: Jevđić J, Raffay V. et. al. Napredna životna podrška ERC Preporuke izdanje 2015. $1^{\text {st }}$ ed. Niel, Belgium: European resuscitation council, 2015.

5. LeBlanc PA, Nadeau A. BET 1: Continuous flow insufflation of oxygen in out-of-hospital cardiac arrest. Emerg Med J. 2018 Jan;35(1):65-66. doi: 10.1136/emermed-2017-207366.1.

6. Izawa $J$ et al. Timing of advanced airway management by emergency medical services personnel following out-of-hospital cardiac arrest: A population-based cohort study. Resuscitation 2018 Jul; 128:16. (https://doi.org/10.1016/j.resuscitation.2018.04.024)

7. Fouche PF, Simpson PM, Bendall J, Thomas RE, Cone DC, Doi SA. Airways in out-of-hospital cardiac arrest: systematic review and meta-analysis. Prehosp Emerg Care. 2014;18(2):244-56.

8. Newell et al. Airway and ventilation management during cardiopulmonary resuscitation and after successful resuscitation Critical Care 2018; 22:190.

9. Soar J, Callaway CW, Aibiki M, Bottiger BW, Brooks SC, Deakin CD, Donnino MW, Drajer S, Kloeck W, Morley PT, et al. Part 4: advanced life support: 2015 international consensus on cardiopulmonary resuscitation and emergency cardiovascular care science with treatment recommendations. Resuscitation. 2015;95:e71-120.

10. Dell'Anna A.M. , Lamanna I., Vincent J.L., Silvio Taccone S.F. How much oxygen in adult cardiac arrest? Crit Care. 2014; 18(5): 555.

11. Sandroni C., D'Arrigo S. Management of oxygen and carbon dioxide pressure after cardiac arrest. Minerva Anestesiol. 2014 Oct;80(10):1105-14. Epub $2014 \operatorname{Jan} 8$.

12. Johnson NJ., Dodampahala K., Rosselot B., et. al. The Association Between Arterial Oxygen Tension and Neurological Outcome After Cardiac Arrest. Ther Hypothermia Temp Manag. 2017 Mar; 7(1):3641. doi: 10.1089/ther.2016.0015. Epub 2016 Jul 6.

13. Lemiale V, Dumas F, Mongardon N, Giovanetti O, Charpentier J, Chiche JD, Carli P, Mira JP, Nolan J, Cariou A. Intensive care unit mortality after cardiac arrest: the relative contribution of shock and brain injury in a large cohort. Intensive Care Med. 2013;39:19721980. doi: 10.1007/s00134-013-3043-4.

14. Sauter CT, Iten N, Schwab PR, Hautz WE. et. al. Out-of-hospital cardiac arrests in Switzerland: Predictors for emergency department mortality in patients with ROSC or on-going CPR on admission to the emergency department. PLoS One. 2017 Nov 16;12(11):e0188180. doi: 10.1371/journal.pone.0188180. eCollection 2017. 